\section{Discussion}

Currently, PRIS is assumed to be related to disruption of fatty acid oxidation caused by impaired entry of long-chain acylcarnitine ester into the mitochondria and failure of the mitochondrial respiratory chain. ${ }^{6}$ Isolated hyperkalemia and acidosis, components of PRIS have been reported from even smaller or average doses of propofol infused over a shorter period of time. ${ }^{7}$ Exact mechanism of isolated hyperkalemia from propofol administration is unclear. In the body, the main store of potassium are the muscles and liver. PRIS usually leads to rhabdomyolysis, with secondary hyperkalemia. However, hyperkalemia has been reported without rhabdomyolysis. ${ }^{8}$ It is hypothesized that mitochondrial fatty acid oxidation disorder could disturb potassium homeostasis because of its relationship with mitochondrial metabolism. ${ }^{9}$ Meanwhile propofol could produce lactic acidosis through the impairment of free fatty acid utilization and mitochondrial activity in the muscles and heart. ${ }^{10}$ The patient was hemodynamically stable without evidence of hypovolemia or any pre-existing infection, thereby ruling out other possible causes of lactic acidosis. Hyperkalemia and acidosis during propofol infusion are harbingers of impending catastrophe, and failure to recognize these early warning signs and discontinuing its infusion would lead to florid PRIS with dangerous consequences.

In the light of the clinical circumstances, blood chemistry and recovery of deranged parameters following discontinuation of propofol infusion, it can be assumed that the patient may have developed PRIS. In this context, the role of serial ABGs and careful ECG monitoring cannot be overemphasized.

\section{Conflict of Interest}

None declared.

\section{References}

1 Parke TJ, Stevens JE, Rice ASC, et al. Metabolic acidosis and fatal myocardial failure after propofol infusion in children: five case reports. BMJ 1992;305(6854):613-616

2 Cremer OL, Moons KGM, Bouman EAC, Kruijswijk JE, de Smet $\mathrm{AM}$, Kalkman CJ. Long-term propofol infusion and cardiac failure in adult head-injured patients. Lancet 2001;357(9250): 117-118

3 Bray RJ. Propofol infusion syndrome in children. Paediatr Anaesth 1998;8(6):491-499

4 Haase R, Sauer H, Eichler G. Lactic acidosis following short-term propofol infusion may be an early warning of propofol infusion syndrome. J Neurosurg Anesthesiol 2005;17(2):122-123

5 Lee JH, Ko YS, Shin HJ, Yi JH, Han SW, Kim HJ. Is there any relationship between hyperkalemia and propofol? Electrolyte Blood Press 2011;9(1):27-31

6 Wolf A, Weir P, Segar P, Stone J, Shield J. Impaired fatty acid oxidation in propofol infusion syndrome. Lancet 2001;357(9256): 606-607

7 Mali AR, Patil VP, Pramesh CS, Mistry RC. Hyperkalemia during surgery: is it an early warning of propofol infusion syndrome? J Anesth 2009;23(3):421-423

8 Kam PC, Cardone D. Propofol infusion syndrome. Anaesthesia 2007;62(7):690-701

9 Wasant P, Matsumoto I, Naylor E, Liammongkolkul S. Mitochondrial fatty acid oxidation disorders in Thai infants: a report of 3 cases. J Med Assoc Thai 2002;85(Suppl 2):S710-S719

10 Bonhomme V, Demoitie J, Schaub I, Hans P. Acid-base status and hemodynamic stability during propofol and sevoflurane-based anesthesia in patients undergoing uncomplicated intracranial surgery. J Neurosurg Anesthesiol 2009;21(2):112-119

\title{
An Infant with Apert Syndrome and Tetralogy of Fallot for Craniosynostosis Correction: Anesthetic Challenges
}

\author{
Karen R. Lionel ${ }^{1}$ Satish K. Sundararajan ${ }^{1} \quad$ Ranjith K. Moorthy ${ }^{2} \quad$ Ramamani Mariappan $^{1}$
}

${ }^{1}$ Department of Anaesthesia, Christian Medical College, Vellore, Tamil Nadu, India

2Department of Neurological Sciences, Christian Medical College, Vellore, Tamil Nadu, India

J Neuroanaesthesiol Crit Care:2021;8:60-62

Published online

July 1,2020
DOI https://doi.org/

$10.1055 / \mathrm{s}-0039-1692735$

ISSN 2348-0548.
Address for correspondence Ramamani Mariappan, MD, DNB, Department of Anaesthesia, Christian Medical College, Vellore 632004, Tamil Nadu, India (e-mail: ramamani@cmcvellore.ac.in).
(C2020. Indian Society of Neuroanaesthesiology and Critical Care. This is an open access article published by Thieme under the terms of the Creative Commons Attribution-NonDerivative-NonCommercial-License, permitting copying and reproduction so long as the original work is given appropriate credit. Contents may not be used for commercial purposes, or adapted, remixed, transformed or built upon. (https://creativecommons.org/licenses/by-nc-nd/4.0/).

Thieme Medical and Scientific Publishers Pvt. Ltd. A-12, 2nd Floor, Sector 2, Noida-201301 UP, India 


Abstract
Keywords
- Apert's syndrome
- tetralogy of Fallot
- craniosynostosis
- paradoxical air
embolism
- tet spell

Apert syndrome (AS) is an autosomal dominant disorder characterized by craniosynostosis, craniofacial anomalies, and symmetrical syndactyly of hands and feet. Ten percent children with AS can have associated congenital cardiac anomalies. Association of complex cyanotic heart disease with craniosynostosis is very rare. So far, only one case has been reported in the literature. The craniosynostosis corrective surgery is associated with the risk of massive bleeding or venous air embolism, which can cause paradoxical air embolism and precipitate cyanotic spell, which makes the anesthesia more challenging. In this report, we present the anesthetic challenges of an 8-monthold infant with AS and tetralogy of Fallot for craniosynostosis correction.
Apert syndrome (AS), popularly known as acrocephalosyndactylia, a rare autosomal dominant disorder characterized by craniosynostosis, craniofacial anomalies, and severe symmetrical syndactyly of the hands and feet. ${ }^{1}$ Ten percent of children with AS can have associated congenital cardiac anomalies. ${ }^{2}$ AS with complex cyanotic heart diseases for craniostenostosis correction surgery is not reported in the literature. So far, only one case of hypoplastic left heart syndrome for craniostenostosis correction has been reported in the literature. ${ }^{3}$ The craniosynostosis corrective surgery is associated with the risk of massive bleeding or venous air embolism (VAE), which can precipitate cyanotic spell and can cause paradoxical air embolism in children with tetralogy of Fallot (TOF) which makes the anaesthetic management a challenging one. We present the anesthetic challenges of an infant with AS and TOF for craniosynostosis correction.

\section{Case Report}

An 8-month-old infant (weight: $8 \mathrm{~kg}$ ) presented with the typical features of AS, such as flattening of bilateral frontal prominences with fused cranial bones, ocular hypertelorism, down-slanting palpebral fissures, and proptotic eyes, depressed nasal bridge, wide nose with a bulbous tip, fused middle and third fingers on the left hand, and fused second and third toes in both feet (-Fig. 1A-C). The child had central cyanosis, with oxygen saturation of $82 \%$. Airway examination revealed short webbed neck with restriction of neck movements. Cardiac examination revealed features of TOF. Echocardiography showed a subaortic ventricular septal defect (5-mm defect) with bidirectional shunting, 20\% aortic overriding with severe infundibular stenosis with a peak gradient of $107 \mathrm{~mm} \mathrm{Hg}$. Computerized tomography of skull revealed fused coronal suture with open sagittal, metopic, and lambdoid sutures. She was posted for bifrontal craniotomy with right frontal orbitotomy. The child was on propranolol $5 \mathrm{mg}$ bid for preventing infundibular spasm.

After consultation with a multidisciplinary team, it was decided to proceed with craniostenostosis correction before the surgical correction for TOF. All standard monitors were connected and induction was carried out using $4 \%$ sevoflurane with $100 \%$ oxygen. Once the child was asleep, an intravenous access was established and the anesthetic plane was deepened with fentanyl, ketamine, and a small dose of propofol. Phenylephrine $(5 \mu \mathrm{g})$ bolus was given along with induction drugs to maintain the systemic vascular resistance (SVR). After confirming the adequate bag and mask ventilation, the child was paralyzed with atracurium, was intubated using a video laryngoscope (C-MAC size 1, video laryngoscope, KARL STORZ, Germany) with 4.5-uncuffed endotracheal tube (EET) which was reinforced with 5.5-mm ETT to prevent kinking (from the angle of mouth to connector level) as described by Singh et al. ${ }^{4}$ A 22-G peripheral venous access, a 24-G right radial arterial line, and a 5.5-F right subclavian triple lumen central venous catheter were inserted and strict measures were taken to avoid air entrainment. Tranexamic acid (20 mg/ $\mathrm{kg}$ ) bolus followed by an infusion at $1 \mathrm{mg} / \mathrm{kg} / \mathrm{h}$ was given to reduce the bleeding. Bilateral scalp block was given using $8 \mathrm{~mL}$ of $0.2 \%$ ropivacaine before the skin incision. Fentanyl (up to $8 \mu \mathrm{g} / \mathrm{kg}$ ) and morphine $(0.75 \mathrm{mg}$ ) and $20 \mathrm{mg} / \mathrm{kg}$ of paracetamol were given for analgesia. Intraoperatively, measures were taken to avoid "Tet Spell" by maintaining the SVR using low dose of noradrenaline $(0.02-0.05 \mu \mathrm{g} / \mathrm{kg} / \mathrm{min})$ and by avoiding factors that can increase the pulmonary vascular resistance (PVR), such as hypercarbia, hypoxia, acidosis, hypothermia, and high positive end expiratory pressure. Intraoperatively, the saturation was maintained between $85 \%$ and $93 \%$ with an inspired oxygen concentration of $60 \%$. The procedure lasted for 4 hours with $170 \mathrm{~mL}$ of blood loss (30\% of blood volume) which was replaced with $100 \mathrm{~mL}$ packed red cell concentrates and $50 \mathrm{~mL}$ of fresh frozen plasma and $25 \mathrm{~mL}$ of cryoprecipitate. Since we were expecting another 50 to $60 \mathrm{~mL}$ of blood loss in the postoperative wound drain and we did not want to dilute the blood with crystalloids, and to avoid postoperative hypotension and coagulopathy, we had given the blood products. The child was hemodynamically stable, warm, and awake at the end of surgery. The trachea was extubated and shifted to high dependency unit with fentanyl $(0.4-0.5 \mu \mathrm{g} / \mathrm{kg} / \mathrm{h})$ and ketamine $(0.02-0.03 \mathrm{mg} / \mathrm{kg} / \mathrm{h})$ infusion for postoperative analgesia. Child had good recovery and got discharged on the 7 th postoperative day. 


\section{Discussion}

AS accounts for $4.5 \%$ of all cases of craniosynostosis and often associated with cardiac and urological anomalies with a prevalence of 1 in 65,000 to 75,000 live births. ${ }^{5}$ There are several anesthetic concerns while anaesthetizing these children. Firstly, they can have upper airway obstruction due to the reduction in the nasopharyngeal size and choanal patency, can have lower airway compromise due to the associated anomalies of the tracheal cartilage. ${ }^{6}$ In some cases, they can even present with severe obstructive sleep apnea and the cor pulmonale. In our case, though the history and the preoperative examination did not reveal airway obstruction, the child required an oral airway to maintain the airway patency soon after induction and an hour after extubation. Secondly, they can have congenital cervical spinal fusion, especially at C5 and C6 (seen in 68\% of cases), can lead to difficult intubation. This infant also had a short and webbed neck with restriction in neck movements which made us select C-MAC video laryngoscope for intubation ( - Fig. 1A, B). Thirdly, premature closure of cranial suture can result in elevated intracranial pressure. So, it is imperative to prevent further increases in the intracranial pressure by assuring a smooth induction, intubation and emergence. Lastly, AS can have associated cardiac anomalies as seen in this case that had TOF. The mortality of children with congenital heart disease undergoing major surgery is $16 \%{ }^{2}$ Since this child had TOF along with AS, measures were taken to maintain adequate preload to stent open the stiff, noncompliant RVOT; the afterload was maintained with noradrenaline infusion to minimize the right to left shunt, thereby promoting pulmonary blood flow; and measures were taken to avoid increase in the PVR which will decrease the pulmonary blood flow, thus worsening the cyanosis.

Specific risks related to craniosynostosis corrective surgery include major blood loss and venous air embolism (VAE) ${ }^{6,7}$ In our patient, tailoring the surgical procedure

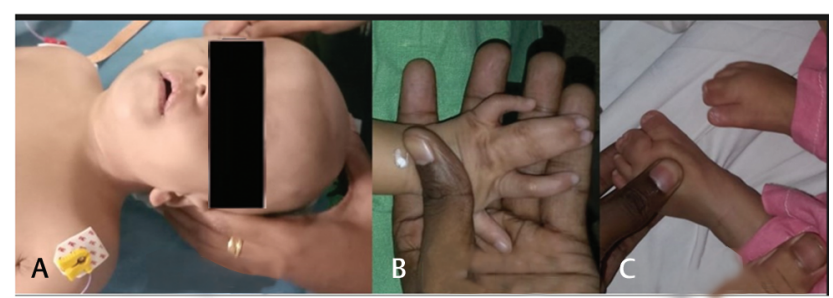

Fig. 1 (A) The infant with Apert syndrome with typical facial features with short and webbed neck. (B) Syndactyly involving the second and third fingers of the left hand. (C) Syndactyly of the second and third toes of both the feet. to involve minimal dissection of the bone over the venous sinuses aided in reducing blood loss. The incidence of VAE has been reported as high as $83 \%$, mostly occurring without hemodynamic compromise and only about 1 to $2 \%$ being clinically significant.? The occurrence of VAE in presence of TOF can cause paradoxical air embolism, which can increase morbidity or mortality significantly.

\section{Conclusion}

A syndromic infant coming for craniosynostosis surgery with an underlying congenital cyanotic heart disease and a difficult airway poses a lot of challenges to the neuroanesthesiologist. Maintaining both the cardiovascular and cerebrovascular homeostasis is of paramount importance for a successful outcome. In our case, smooth induction and extubation, adequate preparedness to face the massive blood loss, appropriate blood, and fluid transfusion to prevent hypovolemia, VAE, administration of low dose of vasopressor to maintain the SVR, and adequate postoperative pain relief all helped in the rapid recovery.

\section{Note}

This case report abstract is submitted as conference paper and was presented in the ISNACC-2019 (Feb 15-17th) at Gurugram, Haryana, India.

\section{Conflict of Interest}

None declared.

\section{References}

1 Cohen MM Jr., Kreiborg S. An updated pediatric perspective on the Apert syndrome. Am J Dis Child 1993;147(9):989-993

2 Hennein HA, Mendeloff EN, Cilley RE, Bove EL, Coran AG. Predictors of postoperative outcome after general surgical procedures in patients with congenital heart disease. J Pediatr Surg 1994;29(7):866-870

3 Bergmans B, Kammeraad JA, van Adrichem LN, Staals LM. Craniosynostosis surgery in an infant with a complex cyanotic cardiac defect. Paediatr Anaesth 2014;24(7):788-790

4 Singh G, Mariappan R, Gautham AK. Buttressing the paediatric endotracheal tube in neonates: a simple but useful technique. J Neurosurg Anesthesiol 2018;30(1):83-84

5 Cohen MM Jr., Kreiborg S, Lammer EJ, et al. Birth prevalence study of the Apert syndrome. Am J Med Genet 1992;42(5):655-659

6 Barnett S, Moloney C, Bingham R. Perioperative complications in children with Apert syndrome: a review of 509 anesthetics. Paediatr Anaesth 2011;21(1):72-77

7 Faberowski LW, Black S, Mickle JP. Incidence of venous air embolism during craniectomy for craniosynostosis repair. Anesthesiology 2000;92(1):20-23 